\title{
QUATRO ÂMBITOS DA CONSTITUIÇÃO DO \\ CONHECIMENTO EM ARTES VISUAIS NA \\ PERSPECTIVA DA ARTE CONTEMPORÂNEA*
}

\section{FOUR FIELDS OF THE CONSTITUTION OF KNOWLEDGE IN VISUAL ARTS IN PERSPECTIVE OF CONTEMPORARY ART}

Maria Regina Johann**

Resumo: Este texto se ocupa do tema da arte contemporânea e sua justificação no ensino das Artes Visuais. Indica conteúdos e propõe questões que poderemos apresentar aos alunos para enfrentar essa abordagem problematizando aspectos acerca da arte contemporânea, tais como: o sistema da arte, o lugar do artista, do mercado e do público, explicitando características artísticas presentes na criação contemporânea, entre elas a mestiçagem, o hibridismo, a apropriação e a recontextualização. Diante disso, justificaremos a presença dessa abordagem na educação por acreditar que conhecer arte contemporânea de modo contextualizado e tensionado em relação à arte da tradição empodera o aluno à compreensão crítica dessa manifestação artística, contribuindo, também, para o entendimento do seu lugar no mundo humano. Para a abordagem desse tema trataremos de quatro âmbitos que envolvem o domínio de uma matéria a ser ensinada: o que é isso (a matéria a ser ensinada)? Como se pode entender isso? Por que isso consta do currículo? O que modifica uma vida sabendo disso? Esses âmbitos serão tratados a partir do conceito de Arte Contemporânea e alguns de seus conteúdos com foco no Ensino Médio.

Palavras-chave: Ensino de Artes Visuais. Conteúdos Conceituais. Mestiçagem. Empoderamento. 
Abstract: This text is concerned with the theme of contemporary art and its justification in the teaching of Visual Arts. Indicates contents and proposes questions that we can provide for students to meet this approach questioning about aspects of contemporary art, such as the system of art, the place of the artist, the market and the public, explaining artistic features present in contemporary creation, including miscegenation, hybridity, appropriation and recontextualization. In view of this, we will justify the presence of the aforementioned approach in education believing that meet contemporary art in a contextualized way and tensioned in relation to art of tradition empowers the learner to critically understand this artistic expression, contributing also to the understanding of their place in human world. To an approach of this theme we will cover four areas that involve the mastery of a subject to be taught: what is this (matter being taught)? How can one understand this? Why this is recorded in the curriculum? What changes in life when you know that? These areas will be treated through the concept of Contemporary Art and some of its contents with a focus on high school.

Keywords: Teaching Visual Arts. Technology Contents. Miscegenation. Empowerment. 


\section{Introdução}

A intencionalidade de uma formação escolar deve poder ser expressa pela intencionalidade do conteúdo da educação, ou seja, do conhecimento a ser aprendido. Habilitar-se a ministrar determinado conteúdo de ensino pressupõe, portanto, alguns domínios que representam a razão de ser dos temas/conceitos a serem ministrados. Nesse sentido, pode-se falar de quatro âmbitos que envolvem o domínio de uma matéria a ser ensinada: o que é isso (a matéria a ser ensinada)? Como se pode entender isso? Por que isso consta do currículo? O que modifica uma vida sabendo disso? Esses âmbitos serão tratados na perspectiva do ensino das Artes Visuais, sendo que para desenvolver esses aspectos tomamos como referência o conceito de arte contemporânea e alguns de seus conteúdos com foco no Ensino Médio.

\section{O que é isso? ou, conceitos e conteúdos sobre arte contemporânea para o ensino médio}

A arte contemporânea está situada em um marco histórico europeu a partir dos anos 1960. Tem como principal característica romper com a arte moderna revisitando o passado, descontextualizando e recontextualizando-o. É uma arte mestiça, caracterizada pelo hibridismo e pela apropriação. Uma das características principais é a recontextualização de ideias e temas e a citação de obras tradicionais (ou elementos delas), o que tem sido uma constante ${ }^{1}$. Também faz parte de suas características a incorporação das TICs (Tecnologias de Informação e de Comunicação) e dos materiais do cotidiano, como objetos, alimentos, sucatas, materiais indus- 
trializados, entre outros. Ainda, faz parte desse universo o uso do corpo como suporte e como forma, procedimentos efêmeros, intervenções urbanas e as interferências em ambientes.

Estas características contemporâneas têm origem na arte dadaísta de Marcel Duchamp ${ }^{2}$ e, de modo especial, em sua atitude ao apresentar um mictório masculino assinado em uma exposição de arte na França, na qual ele mesmo teria sido jurado.

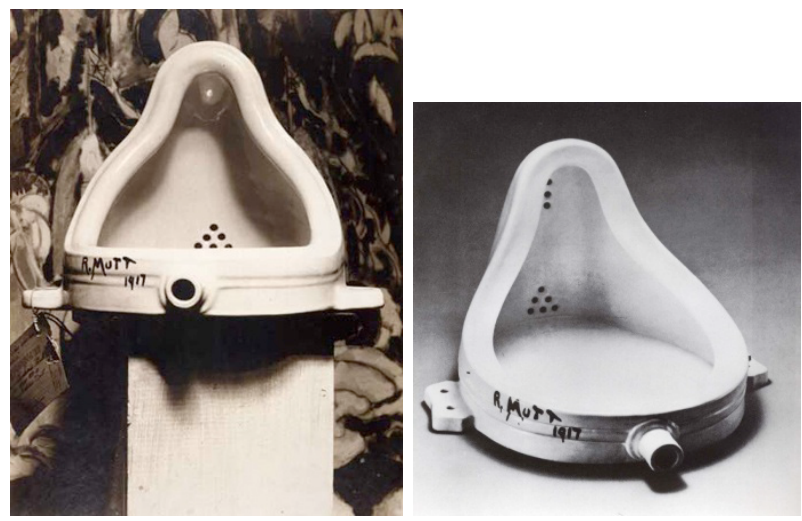

“Fontain", 1917 - Ready-made de Marcel Duchamp ${ }^{3}$

Com este "deslocamento estratégico"4, Duchamp dessacraliza a obra de arte e polemiza seu lugar numa sociedade industrializada e em crise dos valores éticos, uma vez que foi afetada pelas guerras e pela substituição do trabalho artesanal pelas máquinas ${ }^{5}$. Que lugar teria, por exemplo, a pintura em uma sociedade fascinada pela fotografia e em crise em relação às grandes lutas políticas? Diante disso, constata-se que “[...] nos últimos dois séculos, as artes plásticas ocidentais sofreram mudanças extremas que alteraram como nunca sua relação com o mercado, com as instituições culturais e com o público." (TRIGO, 2009, p. 10).

Dada à relevância deste âmbito artístico, podemos mencionar que a arte contemporânea se constitui em conteúdo conceitual da 
Educação Básica e, em especial, assunto a ser desenvolvido a partir do Ensino Fundamental II, com ênfase no Ensino Médio, isto porque nesse tempo de escolaridade o aluno já construiu um repertório conceitual da arte da tradição que o habilita a compreender as rupturas e proposições no âmbito da arte contemporânea.

Assim, podemos elencar como conceitos fundamentais desse âmbito artístico a apropriação, o hibridismo e a efemeridade, isso porque o artista contemporâneo pode ser caracterizado como um catador $^{6}$. Ele, muitas vezes, se apropria dos objetos do cotidiano e ressignifica-os, descontextualizando-os e os colocando nos espaços legitimados da $\mathrm{arte}^{7}$. Sua arte é hibrida porque mistura procedimentos e materialidades, rompendo com linguagens e padrões em que, por vezes, fica difícil definir se a obra é escultura, objeto arte ou interferência, por exemplo. Desses conceitos podemos desmembrar, entre outros, os seguintes conteúdos sobre arte contemporânea:

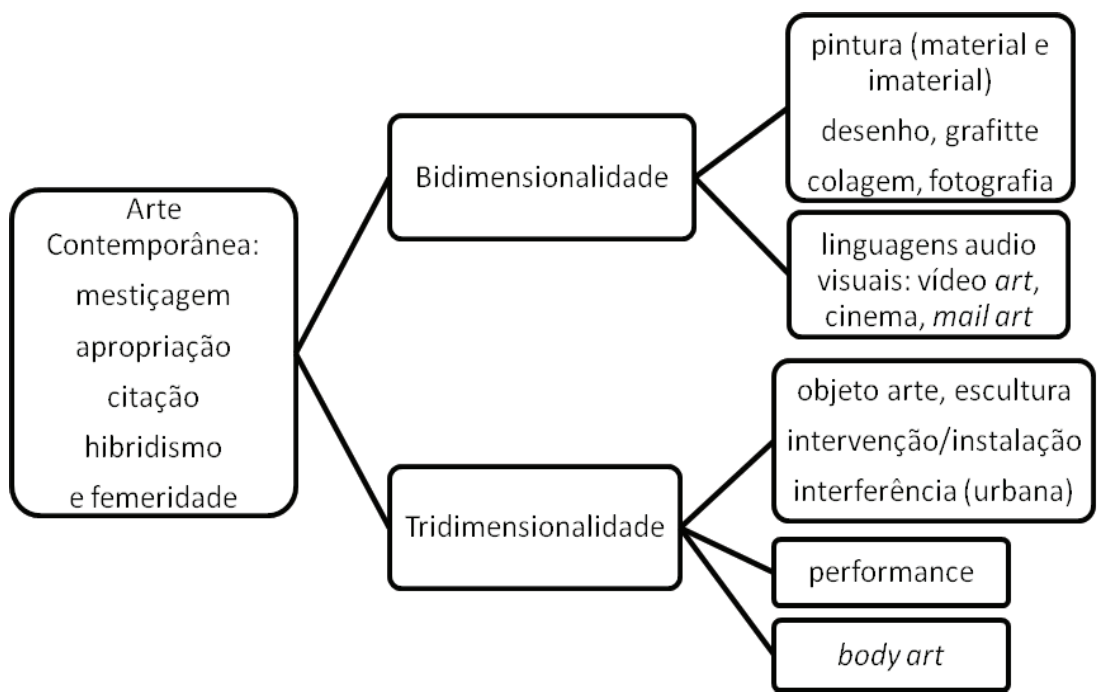

Esses conteúdos conceituais necessitam ser apresentados aos alunos de modo contextualizado, pois é preciso compreender em 
que contexto isso se dá e como podemos pensar tais questões, também em relação ao que acontece em nosso entorno. Assim, o professor apresenta a arte e tematiza sua presença no mundo humano, auxiliando o aluno a perceber como ela se inscreveu em diferentes tempos e concepções artísticas. Mas, também, é válido possibilitar que pensem criticamente sobre o que veem, levantando argumentos sobre a validade de tais obras no âmbito da arte (e da sua tradição) a partir das suas percepções. Quando um professor consegue problematizar a arte ele auxilia os alunos a não só interpretar, mas também julgar a obra e, com isso, emitir um julgamento acerca do valor estético da obra, justificando suas escolhas além do "gosto" ou "não gosto". Com isso possibilitamos que compreendam que a arte, assim como as demais dimensões da vida, é constituída por humanos, ou seja, não por “deuses” e, assim, precisando também ser validada socialmente. Nesse sentido, é pertinente a pesquisa e a apreciação de imagens (reproduções das obras) que ilustrem tais questões e auxiliem na percepção de como isso se dá na especificidade das artes visuais. Por outro lado, é também válido o debate sobre o sistema da arte, apresentando as inter-relações desse universo na perspectiva da arte, do artista, do mercado e da crítica.

\section{Como se entende isso? $\mathrm{Ou}$, a historicidade do conhecimento sobre arte contemporânea}

Na perspectiva de compreensão do estado da arte contemporânea é importante lembrar que na sociedade moderna Ciência e Arte se separam do poder da Igreja e do Estado. Em relação a isso 
Trigo (2009) observa que a crise da arte tem seu início já no século XVIII, pois o Iluminismo abriu caminho para a Revolução Francesa de 1789, afastando do poder a aristocracia e a Igreja, que eram grandes compradoras da arte, ocasião em que também saíram de cena os comerciantes e banqueiros ${ }^{8}$. Mais tarde, com a invenção da fotografia, não só a arte entra em crise, mas o artista também, ficando o atelier sem sentido, esvaziando-se pela falta de discípulos e de grandes compradores.

A Revolução Francesa prometia um mundo melhor explicitado em sua bandeira de lutas: liberdade, fraternidade e igualdade. Mas para o artista esse contexto de liberdade se transformou num pesadelo: sem compromisso com a realidade (já que gozava de liberdade), a realidade também já não tinha mais compromisso com o artista. Assim, a arte passou a ser inútil, não ocupando mais seu lugar de status social e poder.

Arte pela arte? As transformações não cessam, as imagens se multiplicam indefinidamente, estão em toda parte e ao mesmo tempo. Segundo Giulio Argan (1988), a modernidade foi o primeiro período de conflito entre artistas e classe dominante, a nova burguesia; batalha assumida principalmente pelos dadaístas e, conforme Trigo (2009), isso gerou a necessidade de outras estratégias para os ataques, engendrando outras formas de produção artística, afastando-os da pesquisa plástica, o cerne da arte. Nesse sentido, Bonfanti (apud TRIGO, 2009, p. 11) argumenta que "[...] retirar da arte a sua aura era imperioso, pois, dessa maneira, haveria um esvaziamento de seu lugar simbólico. Esvaziada, já não seria como status de poder social à burguesia." Destruindo a pesquisa e a linguagem artística como principal referência da arte, Duchamp nega a essência do que, até então, se entendia como arte. 
Ainda em Trigo (2009) vemos que no século XIX a ciência passa a ser o grande paradigma. Sigmund Freud busca o status de ciência para a psicanálise - perseguindo o rigor da ação. E a arte também busca ficar nesse âmbito. Inflamadas pela ideia de evolução e de fabricação formam-se as Vanguardas Artísticas (expressionismo, cubismo, futurismo, dadaísmo e surrealismo). Surgem os sistemas de arte que carregam a marca da modernidade, da seriação e da fabricação explicitada em “ismos”. Para se afirmar a cada nova revolução, a arte negava o passado recente, rechaçava as linguagens tradicionais, substituindo-as por "novas". Rompia com o passado para eliminar a aura que a longa tradição lhe conferia.

Conforme Trigo (2009), esse foi o grande golpe nas artes, visto que isso afetou o processo de criação. O desejo de fabricação e de superação do passado tornou-se inviável para o âmbito artístico. Como indaga Robert Hughes (apud TRIGO, 2009), se houvesse progresso na arte que interesse teria a arte renascentista hoje, meio milênio depois? O artista, ao produzir suas obras, está em diálogo com a cultura, com o trabalho de outros artistas, tanto dos vivos quanto dos mortos; afinal, somos produtos da história, ou seja, "a arte carrega o mundo em suas costas"”, e isso não é possível negar.

Duchamp anuncia os tempos narcísicos, pois, conforme Trigo (2009), ele desloca para o artista, para o gesto e para o corpo do artista, a aura que antes pairava na obra de arte. Também rompe totalmente as amarras com o passado; agora a obra em si já não tem aura nem glamour. Para Duchamp a obra se torna uma mera ilustração porque elege a razão como guia para a feitura da obra; "sai da moda" o campo das sensações. "Essa inversão foi um golpe de morte no processo criador. Na obra de arte, o conceito se estrutura dentro da pesquisa de linguagem diária, ele nasce da obra, junto com ela [...].” (TRIGO, 2009, p. 12). 
Essa questão aponta que “[...] seria Narciso a própria obra de arte, seu gesto, seu corpo. Narciso morrerá observando sua própria imagem.” (TRIGO, 2009, p. 13). Sem aura, sem a dimensão do sagrado e sem a vida, o que sobra para a arte? Para que arte? Sem a polarização do mundo (capitalismo e socialismo - depois da queda do Muro de Berlim) que ainda sustentava a existência das utopias, as vanguardas perdem seu sentido contestador e utópico. Duchamp levou isso à radicalidade: Negou a arte!

Ao colocar bigodes na reprodução daquela que é considerada uma das maiores referências da arte acadêmica, a Mona Lisa, Duchamp dessacralizou a aura da obra e negou a tradição.

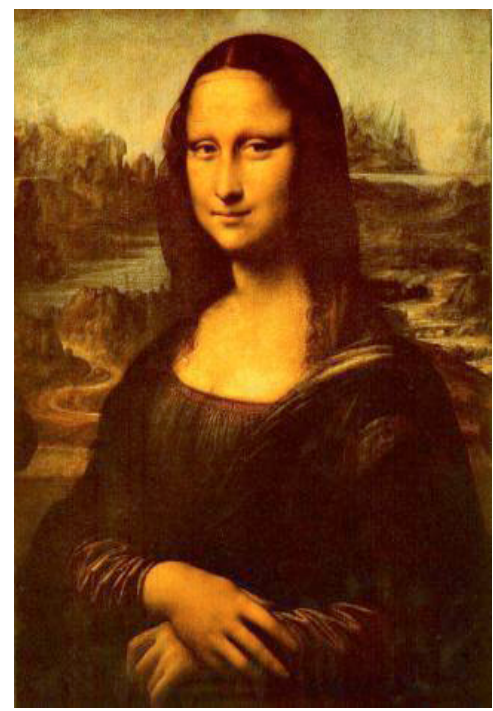

Mona Lisa, 1503 - L. Da Vinci ${ }^{10}$

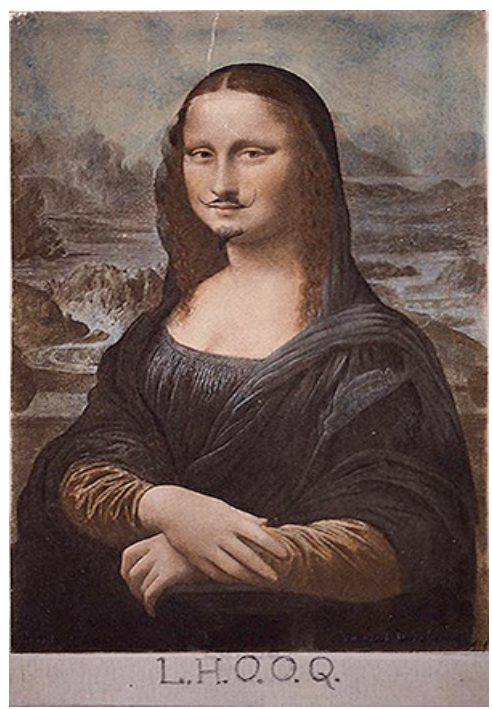

L.H.O.O.Q., 1919 - M. Duchamp ${ }^{11}$

Diante disso, ficou para o artista contemporâneo o vazio deixado por Duchamp e o desafio de dar outro sentido à arte, diferente daquele sobre o qual ela havia se justificado por muitos séculos. No entanto, o que vemos atualmente é muita repetição ducham- 
piana, ou seja, a arte contemporânea tem se mostrado distante do público, e não raras vezes, enfadonha. Vejamos o que Afonso Romano de Sant'Anna (2003, p. 73) comenta acerca da atitude duchampiana:

Marcel Duchamp deu um xeque-mate na arte há quase 100 anos. Desde então, ela ficou paralisada, prisioneira, dependente de uma solução que teria que passar por uma desconstrução do impasse que ele criou. Duchamp encurralou o conceito de arte da época ao convencer seu auditório que tudo era arte, desde que alguém assim o quisesse, desde que o artista apusesse em qualquer objeto, modificando ou não, sua assinatura. No instante em que, atônitos, seus interlocutores e, depois, as gerações vindouras, caíram neste jogo, a arte, como o rei, ficou imobilizada num oxímoro e numa tautologia, pois se tudo é arte, nada é arte.

Também Ferreira Gullar, que é artista e poeta, comenta sua percepção sobre a arte contemporânea, em particular, sobre o que Duchamp deixou como herança para a geração de artistas de hoje:

Quem abandona a linguagem artística e quer fazer arte não faz. Pode se expressar, que é outra coisa. Eu me expresso berrando, chorando, dando soco na parede. Toda arte é expressão, mas nem toda expressão é arte. Quando você fala na arte de cozinhar, na arte de falar, isso implica um saber fazer, um domínio e uma elaboração, um questionamento e um trato com a linguagem. O homem é uma invenção de si mesmo, ele se inventa, inclusive usando instrumentos que ele próprio criou, como as linguagens. Quando eu deixo de usar as linguagens simbólicas criadas pelo homem e dou voz à natureza, abdico da minha capacidade humana de formular as coisas. ${ }^{12}$

Gullar nos faz pensar sobre a poiética que o artista desenvolve e se constitui na sua poética, na sua linguagem e obra, alertando 
para aquilo que é inerente à arte e, sem a qual, ela passa a ser outra coisa.

Sinceramente, o que acrescenta à nossa alegria, à beleza do mundo, à nossa necessidade de sobrevida um urinol de botequim (o poeta se refere à obra Fonte, de Marcel Duchamp...). Essa obra é uma ilusão. Não dura mais 200 anos. A Mona Lisa já tem 500. Quando Leonardo da Vinci pintou a Mona Lisa, colocou ali uma película de sonho, de fantasia. Criou uma coisa que não existia no mundo. Fez um mundo mais bonito, mais maravilhoso. Não posso comparar isso com o cara que colocou bigode na Mona Lisa. É ridículo. Você entende como um momento de rebeldia, de irreverência, mas dar o valor que se quer dar a isso é ridículo, é subestimar o ser humano, é a genialidade do Leonardo da Vinci pisoteada por uma cretinice, por uma piada. ${ }^{13}$

Por outro lado, destacamos também visões distintas das até então apresentadas, como o comentário do psicanalista Edson de Souza (1999) em relação aos juízos sobre artes plásticas apresentadas por Gullar: "[...] toda significação é produzida num encontro com o discurso social. São os efeitos produzidos por essas obras nesse meio social que as legitimam e as reconhecem como obras. Não podemos, portanto, furtar-nos à história. [...] O desafio do artista é a transmissão de uma experiência." ${ }^{14}$

Souza (1999) também aponta para a sensibilidade de reconhecer o testemunho de uma herança e pergunta se não será este o século de Duchamp.

[...] as obras de Arte que ficam para a posteridade representam o espírito de seu tempo. Ezra Pound descrevia o artista como a antena de sua época. O artista antecipa esse horizonte com aquilo que faz com sua mão e com sua cabeça, pois arte é pensamento. A obra nos olha, a obra nos pensa, a 
obra nos interpela. O certo é que nossas respostas a ela são sempre insuficientes. Essa parece ser a mais nobre missão do artista, tão bem anunciada na célebre frase de Leonardo da Vinci: 'A arte diz o indizível, exprime o inexprimível, traduz o intraduzível'15.

Por fim, inserir o aluno nesse debate é proporcionar-lhe elementos e critérios para conhecer e julgar. Refletir sobre a arte neste contexto é compreender que ela também se transforma, afeta e é afetada socialmente. A arte contemporânea é vista pela maioria, inclusive muitos professores, como estranha, difícil, exótica ou elitista. Com isso, ela, muitas vezes, fica fora dos currículos escolares, alijando os alunos deste conhecimento significativo que possibilita a fruição e empodera ao julgamento estético da arte da qual o aluno é contemporâneo.

\section{Por que isso consta do currículo? Ou, por que arte (contemporânea) na escola?}

O primeiro argumento que apresento em defesa da arte na escola diz respeito ao âmbito linguístico. A arte é linguagem e como tal merece ser conhecida ${ }^{16}$. Como linguagem se estrutura em códigos específicos que podem ser conhecidos, aprendidos e vivenciados, através das artes visuais, da dança, da música e do teatro.

Por ser linguagem comunica, informa e expressa ideias, sentimentos, pensamentos e percepções de mundo. Por isso também é conhecimento, uma vez que apresenta outras dimensões do mundo humano, proporciona conhecimento conceitual, promove pensamento (crítico), indagação e relações interdisciplinares. 
Nesse âmbito o componente curricular Arte contempla as diferentes expressões artísticas da humanidade, contribuindo para que o aluno se reconheça como herdeiro de uma tradição artística e cultural inscrita em um âmbito linguístico e histórico. Quando a arte ajuda o aluno a se reconhecer enquanto parte de uma comunidade, herdeiro de uma tradição e potencialmente capaz de compreender o seu sentido no mundo humano, podemos afirmar que ela educa. Educar, nessa perspectiva “[...] é, sobretudo, 'colocar em relação, para que cada um seja desafiado a buscar o sentido das coisas e a descobrir sua singular 'pertença ao mundo."' (ALMEIDA, 2011, p. 220).

O currículo é o espaço político em que podemos propor e justificar o que entendemos por educação e conhecimento. Nele devemos articular uma série de dimensões que consideramos imprescindíveis para a formação dos indivíduos. Nesse sentido, cada matéria comparece com sua proposta e, na especificidade de cada área de conhecimento, compõe aquilo que idealizamos como o conjunto de saberes necessários para que o aluno gradativamente vá construindo saberes e autonomia e, possa, futuramente, participar do mundo comum com ética, conhecimento e compromisso social.

Diante disso, podemos concluir que a "matéria de ensino" é um pedaço de mundo que o professor deve conhecer bem para apresentar aos alunos, concedendo-lhes o direito de se apropriarem, compreenderem e encontrarem razões num mundo que é aberto e no qual podemos nos entender continuamente. Nesse âmbito, o professor professa, ou seja, conta o mundo às novas gerações sem a pretensão de dizer para onde vamos e como devem usar a tradição, pois reduzi-la àquilo que ela pode resolver agora é instrumentalizar toda a tradição que herdamos à imediatez do presente, com o que roubamos do jovem o direito de imprimir sua percepção no mundo ${ }^{17}$. 
Brayner (2008, p. 15) observa que compete à escola “[...] oferecer aos seus egressos as competências necessárias a uma participação qualificada no espaço público.” Nessa direção, o professor é mediador entre o mundo e o aluno, preserva e apresenta certas tradições culturais públicas que a humanidade dá valor. Assim, o professor de arte comparece com sua experiência, sua história e com a autoridade que conquista dando o testemunho sobre a tradição, sempre em diálogo com a contemporaneidade. Por outro lado, quando tematiza a arte contemporânea e a faz em relação à tradição, o professor possibilita ao aluno elementos para conhecer sobre arte e também compreender o sentido dela no cotidiano, na vida dos homens e das mulheres. Mas, também, ao possibilitar o debate sobre a crítica de arte contemporânea, ou seja, o que é arte hoje, quem é o artista e por que algo se constitui em arte, o professor empodera o aluno a se posicionar diante do que vê na mídia, nos espaços urbanos, nas exposições, enfim, no cotidiano. Com isso, acreditamos que os sentidos se produzem e aquilo que outrora era estranho ou "sem sentido" passa a assumir novas configurações.

\section{O que modifica uma vida sabendo disso? Ou, por que conhecer arte contemporânea?}

A arte não serve a nada (ou pelo menos não deveria servir)! Ela tem um fim em si mesma. Sua relevância está justamente na sua gratuidade e autonomia diante das necessidades básicas da existência. Por isso ela nos põe diante do imponderável, do estranho, do sensível, do poético e da beleza (mesmo que seja trágica ou repugnante). Uma boa obra nos apresenta o mundo, possibilita 
apreender nuances da vida por meio de plasticidades próprias a ela. Por isso, uma pintura pode nos comover, uma escultura fazer sonhar. Uma boa obra, por isso, não ilustra ou exemplifica a realidade, mas acrescenta algo a ela, ou seja, a arte é o ente que produz interrogação, que produz sentidos em que o ser emerge, ou como observa Gadamer (2010) "a obra precisa ser integrada à autocompreensão de cada um", uma vez que "alguém diz algo a alguém". A arte, ao mesmo tempo em que renega a tradição, bebe na sua fonte, e permanece no mundo dos homens enquanto habita na linguagem. Quando nada mais se diz sobre ela, deixa de existir no mundo, morre!

Nessa perspectiva a educação tem por tarefa apresentar o universo da arte aos alunos e garantir a continuidade do mundo e, nele, o da arte! Por isso educamos não para que os alunos se adaptem, mas para que conheçam. Assim, a arte não é instrumento e não podemos transformá-la em uma ferramenta para a transformação social ou para politizar o aluno. Em Almeida (2011) encontramos um argumento de Hannah Arendt em relação ao ensino de literatura que nos serve também para pensarmos o lugar da arte na escola. Ela argumenta que no ensino se deve "ler os clássicos por amor" e não porque se procura neles soluções para quaisquer problemas, pois o significado das coisas surge na relação com os contemporâneos e com os que nos antecederam. Não instrumentalizar a arte não significa "[...] que não se retirem conhecimentos úteis para a vida cotidiana e o mundo do trabalho dos currículos escolares, nem que os alunos não devam desenvolver competências e habilidades que os capacitem a resolver problemas, mas que não podemos submeter tudo a um mesmo critério.” (ALMEIDA, 2011, p. 175). A autora sustenta que "quando o 'afim de' torna-se 
o conteúdo do 'em razão de’ há uma perda de sentido”, visto que, para Arendt (2010), “[...] a utilidade instituída como significado gera a ausência de significado." (ALMEIDA, 2011, p. 174).

Almeida (2011) sugere ainda que descubramos as preciosidades que queremos mostrar aos alunos, contribuindo para que construam sentidos sobre a herança que recebem e possam, assim, amar o mundo ao ponto de, equilibradamente, preservá-lo e transformá-lo. No âmbito do ensino de arte contemporânea podemos buscar testemunhos para julgar ou exemplificar o reconhecimento à tradição e o amor mundi ${ }^{18}$ em uma pintura, um objeto, uma interferência urbana, uma performance ou um vídeo instalação, por exemplo. E isso pode se dar na medida em que o aluno conhece bem o assunto a partir de competências que lhe garantem referências e critérios para compreender as motivações da arte habitar o mundo dos homens.

Assim, espera-se que a educação escolar forneça "[...] um mínimo de competências para que os indivíduos possam vir a se interessar e a participar das decisões públicas.” (BRAYNER, 2008, p. 111). Competências que Brayner aponta como:

[...] construir uma relação com o mundo da cultura (e da Arte) que permita entender as diferentes sensibilidades, concepções, entendimentos que ao longo das gerações constituíram o mundo comum; uma competência que franqueie o acesso a uma intersubjetividade responsável entre interlocutores dispostos a participar do debate público; ainda, uma competência que permita a compreensão e a inserção qualificada num mundo de vertiginosos avanços e mudanças tecnológicas e, por fim, uma competência capaz de interrogar os próprios fundamentos de nossas certezas sociais. (BRAYNER, 2008, p. 111). 
Uma educação que desenvolva tais competências nos alunos com certeza melhora a vida, pois acreditamos que a arte também contribui para que se veja a realidade em diferentes perspectivas. Ela amplia os horizontes do cotidiano e, não raras vezes, nos salvou das barbáries da razão instrumental. Um aluno que apreende dimensões da vida na perspectiva da arte tem seu mundo mais alargado e sensível, uma vez que arte cavoca mais fundo possibilitando inter-relações com diferentes âmbitos da vida em sociedade. E, pela própria natureza interdisciplinar da arte, ela possibilita desconstruir valores absolutizantes tencionando percepções e ideias acerca do mundo humano.

\section{Elementos para continuar pensando acerca do ensino da arte contemporânea na perspectiva de uma educação para a compreensão da arte e seu sentido no mundo humano}

Tratar da arte contemporânea e sua justificação no ensino das Artes Visuais requer a explicitação de objetivos e argumentos coerentes para o contexto da arte/educação contemporânea em relação ao lugar/sentido da arte no mundo humano e, em especial, na vida dos alunos.

Diante disso, explicitamos o lugar da arte contemporânea no contexto social observando o sistema da arte em que se evidenciam as complexidades do trabalho do artista, da sua relação com o mercado, com a crítica e, também, com o público. Com isso apontamos para a relevância da tematização desse assunto de modo contextualizado e livre de preconceitos, por acreditar que com isso se possibilita desmistificar aspectos em relação à figura do artista 
e de sua ação como ser no mundo. Consideramos que uma abordagem dessa natureza permite que professores e alunos tratem a arte como uma manifestação de humanos e, por isso, também, incompleta, ou seja, nem sempre a arte está livre de influências externas ao seu próprio universo e, nem sempre o artista cria sem se submeter às imposições do mercado.

Também, mencionamos que ensinar arte contemporânea requer, do professor, o domínio de saberes que lhe asseguram competências para apresentar o assunto de modo consistente e adequado ao âmbito da educação escolar. Assim, do professor se requerem saberes específicos, uma vez que ele participa de uma comunidade de saberes e necessita, por isso, justificá-los no contexto da educação e na perspectiva de um currículo que contribua para um ensino com perspectiva crítica, transformadora e ética. Para tanto, conhecer a matéria e justificá-la no âmbito da educação é pressuposto para ensinar e, também, é fonte de autoridade do professor, uma vez que ele testemunha sua aprendizagem ensinando às novas gerações sua compreensão sobre a tradição que herdou. Assim, o professor fala de um lugar e, ao ocupar esse lugar com competência, assume sua tarefa de educador com compromisso social.

Do mesmo modo, um currículo que contempla o ensino da arte contemporânea possibilita ao aluno a percepção e compreensão da arte de seu tempo. Um currículo dessa natureza empodera o jovem a conhecer e a pensar criticamente sobre o que é arte hoje em relação à arte da tradição; quem é o artista, qual o seu lugar numa sociedade pós-moderna e fortemente determinada pelo consumo e pela objetificação das pessoas e de seus desejos.

Diante disso, reafirmamos a relevância de ensinar sobre arte, mesmo quando a sociedade a desqualifica socialmente na pers- 
pectiva de "se dar bem profissionalmente". Também, acreditamos que a arte pode ser uma possibilidade de ampliar a percepção sobre os diferentes modos de ver o mundo humano, pois ela mostra a complexidade e a diversidade de "ser humano". E, por fim, pensamos que a arte pode alargar a compreensão de conhecimento na medida em que, da sua natureza, possibilita ao aluno conhecer e viver experiências que desvelam que somos, também, estéticos e poéticos e, que no âmbito da arte, "as verdades" necessitam ser revalidadas em argumentos que busquem referências para além da ciência, da religião, da política ou da história.

\section{Referências}

ALMEIDA, Vanessa Sievers. Educação em Hannah Arendt. Entre o mundo deserto e o amor ao mundo. São Paulo: Cortez, 2011.

ARENDT, H. Entre o passado e o futuro. 5. ed. São Paulo: Perspectiva, 2002.

ARGAN, Giulio Carlo. Arte e crítica de arte. Lisboa: Imprensa Universitária, 1988.

BARBOSA, Ana Mae (Org.). Arte/educação contemporânea: consonâncias internacionais. São Paulo: Cortez, 2006.

BOUFLEUER, José Pedro. A docência como testemunho da própria aprendizagem. In: FÁVERO, Altair; DALBOSCO, Claudio; MARCON, Telmo (Orgs.). Sobre filosofia e educação: racionalidade e tolerância. Passo Fundo: Editora da Universidade de Passo Fundo, 2006. p. 365-377.

. Docência na educação superior. Material didático. Programa de Pós-graduação em Educação nas Ciências. Ijuí: Unijuí, 2012.

BRAYNER, F. Educação e republicanismo: experimentos arendtianos para uma educação melhor. Brasília, DF: Líber, 2008. 
G1. 'Mona Lisa jovem', suposta pintura de Da Vinci, é apresentada na Suíça. 26 set. 2009. Disponível em: <http://g1.globo.com/pop-arte/ noticia/2012/09/mona-lisa-mais-jovem-sera-apresentada-em-genebra. html>. Acesso em: mar. 2013.

GADAMER, Hans-Georg. Hermenêutica da obra de arte. Tradução Marcos Antônio Casanova. São Paulo: Martins Fontes, 2010.

GARCIA, C.; FENSTERSEIFER, P. E. Diálogo na política e na educação republicana. Revista Diálogo, Ética e Educação, n. 19, jul./dez. 2011.

GONZÁLES, F. J.; FENSTERSEIFER, P. E. Entre o "não mais" e o "ainda não": pensando saídas do não-lugar da EF escolar. Cadernos de Formação RBCE, n. 1, set. 2009.

GULLAR, Ferreira. Entrevista a Eduardo Veras e Luiz Antônio Araujo. Jornal Zero Hora. Segundo Caderno CULTURA, 1999.

HERNÁNDEZ, Fernando. Catadores da Cultura Visual: uma proposta para uma nova narrativa educacional. Porto Alegre: Mediação, 2007.

MARCELDUCHAMP.NET. L.H.O.O.Q. [s.d.]. Disponível em: $<$ http:// www.marcelduchamp.net/L.H.O.O.Q.php>. Acesso em: mar. 2013.

SANT'ANNA, Afonso Romano de. Desconstruir Duchamp: a arte na hora da revisão. Rio de Janeiro: Vieira \& Lent, 2003.

TRIGO, Luciano. A grande feira: uma reação ao vale-tudo na arte contemporânea. Rio de Janeiro: Record, 2009. 


\section{Notas}

* Este texto é resultados de uma sistematização do componente Docência na Educação Superior ministrado pelo professor Dr. José Pedro Boufleuer no curso de doutorado. Unijuí - Programa de Pós-Graduação em Educação nas Ciências. ** Professora do Departamento de Humanidades e Educação da Unijuí. Graduada em Educação Artística - Habilitação Artes Plásticas, mestre e doutoranda em Educação pelo Programa de Pós-Graduação em Educação nas Ciências da Unijuí. Coordenadora pedagógica do Polo Unijuí da Rede Arte na Escola e Integrante do Grupo de artistas Artes Seis (Ijuí). E-mail: <maria. johann@unijui.edu.br>.

${ }^{1}$ Nesse aspecto é possível afirmar que isso tem se constituído quase como uma norma para muitos artistas contemporâneos, bastando, para isso, olhar o que se tem produzido nos últimos anos.

${ }^{2}$ Marcel Duchamp foi criador dos que significa se apropriar de objetos do cotidiano, muitos deles criados em série pela indústria, e ressignificá-los no âmbito das artes.

${ }^{3}$ Disponível em Marcelduchamp.net ([s.d.]).

${ }^{4}$ Sobre isso, ver Sant'Anna (2003).

${ }^{5}$ No entanto, é bom lembrar, conforme observa Trigo (2009), que Duchamp ambicionava ser um grande pintor e, ao destruir a pintura, atingia um dos maiores artistas do século XX, nada mais que Pablo Picasso.

${ }^{6}$ Tomo emprestada a metáfora de Hernández (2007).

${ }^{7}$ Salas de exposição, galerias, museus.

${ }^{8}$ Podemos citar, como exemplo, a Família dos Médici, que por mais de quatrocentos anos fomentou a arte na Itália (TRIGO, 2009).

${ }^{9}$ Afirmação que se inspira em reflexões de Claudio Boeira Garcia, professor do Programa de Pós-Graduação em Educação nas Ciências da Unijuí, 2012.

${ }^{10}$ Disponível em G1 (2009).

${ }^{11}$ Disponível em Marcelduchamp.net ([s.d.]).

${ }^{12}$ Este depoimento faz parte de uma entrevista de Ferreira Gullar (1999).

${ }^{13}$ Entrevista de Ferreira Gullar (1999).

${ }^{14}$ Texto publicado na Edição de Zero Hora - Segundo Caderno CULTURA, em 1999.

${ }^{15}$ Texto publicado na Edição de Zero Hora - Segundo Caderno CULTURA, em 1999.

${ }^{16}$ Isto não significa dizer que se ensina a ser artista ou a fazer arte, mas a conhecer sua especificidade e vivenciar suas possibilidades escolares.

${ }^{17}$ Ideias proferidas pelo professor José Pedro Boufleuer no componente Docência na Educação Superior no curso de doutorado, 2012. Unijuí - Programa de PósGraduação em Educação nas Ciências.

${ }^{18}$ Para Hannah Arendt (2002), o ponto decisivo da educação é o nosso amor ao mundo e às crianças, ou seja, educação e amor como complementaridades. Para educar as crianças é preciso, antes, amar o mundo e apostar no cuidado para com 
ele. O amor ao mundo não é uma escolha natural, é uma aposta que fazemos. Esse é o testemunho que os adultos deixam aos que chegam, apresentando aos infantes o mundo que os acolhe e do qual futuramente poderão cuidar. 